\title{
Synthesis, characterization, and application of nickel oxide/CNT nanocomposites to remove $\mathrm{Pb}^{2+}$ from aqueous solution
}

\author{
T. Navaei Diva ${ }^{1} \cdot$ K. Zare $^{1}$ (D) F. Taleshi ${ }^{2} \cdot$ M. Yousefi ${ }^{1}$
}

Received: 9 June 2017/ Accepted: 26 July 2017 / Published online: 31 July 2017

(c) The Author(s) 2017. This article is an open access publication

\begin{abstract}
In this study, the efficiency of nickel oxide/carbon nanotube $(\mathrm{NiO} / \mathrm{CNT})$ nanocomposite to remove $\mathrm{Pb}^{2+}$ from aqueous solution is investigated. $\mathrm{NiO} / \mathrm{CNT}$ nanocomposite was prepared using the direct coprecipitation method in an aqueous media in the presence of CNTs. Samples were characterized using simultaneous thermal analysis (STA), X-ray diffraction (XRD), filed emission scanning electron microscopy (FESEM), and BrunauerEmmett-Teller (BET). To optimize the adsorption of $\mathrm{Pb}^{2+}$ ions on $\mathrm{NiO} / \mathrm{CNT}$ nanocomposite, the effects of different parameters including $\mathrm{pH}$, contact time, initial concentration of $\mathrm{Pb}^{2+}$, and adsorbent mass-were also investigated. The optimum $\mathrm{Pb}^{2+}$ removal efficiency on $\mathrm{NiO} / \mathrm{CNT}$ nanocomposite is achieved under experimental conditions of $\mathrm{pH} 7$, contact time of $10 \mathrm{~min}$, initial $\mathrm{Pb}^{2+}$ concentration of $20 \mathrm{ppm}$, and adsorbent mass of $0.1 \mathrm{~g}$. The experimental data showed that the $\mathrm{Pb}^{2+}$ ions adsorption of $\mathrm{NiO} / \mathrm{CNT}$ nanocomposite was through a Freundlich isotherm model rather than a Langmuir model. The kinetic data of adsorption of $\mathrm{Pb}^{2+}$ ions on the adsorbent was perfectly shown by a pseudo-second-order equation, to indicate their chemical adsorption. Thermodynamic parameters such as $\Delta G^{\circ}, \Delta H^{\circ}$, and $\Delta S^{\circ}$ were also measured; the obtained values showed that the adsorption was basically spontaneous and endothermic.
\end{abstract}

K. Zare

k-zare@sbu.ac.ir

1 Department of Chemistry, Science and Research Branch, Islamic Azad University, Tehran, Iran

2 Department of Physics, Qaemshahr Branch, Islamic Azad University, Qaemshahr, Iran
Keywords Removal · Adsorption · Carbon nanotubes · Composite $\cdot$ Heavy metals

\section{Introduction}

Water, which is one of the main elements in the environment, is highly exposed to contamination. Among water pollutants, heavy metal cations, including $\mathrm{Pb}^{2+}, \mathrm{Cd}^{2+}$, $\mathrm{Cr}^{3+}, \mathrm{Cr}^{6+}, \mathrm{Co}^{2+}, \mathrm{Cu}^{2+}, \mathrm{Fe}^{3+}, \mathrm{Ni}^{2+}$ and $\mathrm{Zn}^{2+}$, are extremely toxic and non-biodegradable. These are commonly discharged into water sources and environment via either natural or industrial wastes. Today, elimination of water sources from such cations is among the main challenges faced by researchers and environmentalists. The accumulation of these metal cations in living organisms causes many physiological disorders [1]. The permitted level of $\mathrm{Pb}^{2+}$ in drinking water is $0.01 \mathrm{mg} \mathrm{L}^{-1}$ [2]. The exposure of human body organs to high concentrations of $\mathrm{Pb}^{2+}$ can result in anaemia, mental disorder, and renal and liver diseases.

Several different methods have been introduced and used for heavy metal removal [3], i.e. chemical precipitation, ion exchange, reverse osmosis, membrane-based processes, evaporation, solvent extraction, and adsorption. The efficiency of some of these methods is reduced due to major drawbacks including low removal efficiency and causing side effects that lead to new environmental issues.

In recent years, metal oxide nanoparticles especially metal oxide/CNT nanocomposites have attracted a good deal of persistent interest because of their unique chemical, physical, electrical, and thermal properties [4-6]. These materials are widely used in several areas, including chemistry, physics, material science, biology, medicine, and environment $[7,8]$. 
Metal oxide nanoparticle and metal oxide/CNT nanocomposite adsorbents have been applied for the removal of heavy metals from aqueous solutions. These adsorbents are economically more affordable and also more environment-friendly [9-12].

The amount of heavy metal uptake is directly associated with the total amount of active sites available on the adsorbent; a decrease in metallic nanoparticle dimensions increases their surface-to-volume ratio and consequently increases the active surface area for adsorption. In this regard, the utilization of appropriate substrate material in the synthesis procedure of metal oxide nanoparticles can prevent agglomeration, decrease the diameter of nanoparticles, and change the cluster-like morphology of nanoparticles to a powdered morphology. Therefore, the obtained nanocomposite with larger specific surface area and higher adsorption capacity can be employed as a suitable adsorbent for heavy metal removal.

Due to high surface-to-volume ratio, CNTs are considered as great substrates for the nucleation and growth of nanoparticles with control over diameter distribution [13-16]. One of the main challenges encountered when CNTs are used as the support material for nanoparticle synthesis is the hydrophobicity of their surface. In this regard, surface functionalization of CNTs for the generation of covalent bonds and further attachment of oxide nanoparticles seems to be of great significance [17-19]. The functionalization of CNTs is commonly performed using the chemical oxidation process introducing functional groups such as $-\mathrm{COOH}, \mathrm{C}-\mathrm{O}, \mathrm{C}=\mathrm{O}$, and $-\mathrm{OH}$ on the surface of CNTs; such groups act as active surface sites for metal attachment [20, 21]. NiO nanostructure can be synthesized through various methods such as co-precipitation [22], sol gel [23], hydrothermal [24], spray pyrolysis method [25], and chemical precipitation [26]. In this study, NiO/CNT nanocomposite was synthesized by chemical precipitation method, which was simple and cost efficient.

$\mathrm{NiO} / \mathrm{CNT}$ nanocomposite was applied as an adsorbent to remove $\mathrm{Pb}^{2+}$ from aqueous solution. However, $\mathrm{pH}$, contact time, adsorbent dosage, and initial concentration of $\mathrm{Pb}^{2+}$ were the parameters, the effects of which on adsorption uptake have been investigated.

\section{Experiment}

\section{Materials}

Lead nitrate $\left[\mathrm{Pb}\left(\mathrm{NO}_{3}\right)_{2}, 99.5 \%\right]$, nickel chloride hexa-hydrate $\left(\mathrm{NiCl}_{2} \cdot 6 \mathrm{H}_{2} \mathrm{O}, 98 \%\right)$, sodium hydroxide $(\mathrm{NaOH}$, 99\%), CNTs (MWCNTs, US4309, $20<d<30 \mathrm{~nm}$,
$\mathrm{SSA}=264 \mathrm{~m}^{2} \mathrm{~g}^{-1}, 95 \%$ ), and sulphuric (95-97\%), nitric $(60 \%)$, and hydrochloric $(37 \%)$ acids were applied without further purification.

To synthesize NiO/CNT nanocomposite, the surface of CNTs was functionalized as follows: initially, the desired amount of CNTs was added to the mixture of sulphuric/nitric/hydrochloric acids $(6 \mathrm{M})$ and ultrasonicated for $30 \mathrm{~min}$. The obtained mixture was stirred for $2 \mathrm{~h}$ at temperature of $80^{\circ} \mathrm{C}$ and was then filtered and washed with deionized water until the $\mathrm{pH}$ reached 7 . Finally, the functionalized CNTs were dried in an oven at $120^{\circ} \mathrm{C}$.

For $\mathrm{NiO} / \mathrm{CNT}$ nanocomposite preparation with 1:1 weight ratio, $3.2 \mathrm{~g}$ of $\mathrm{NiCl}_{2} \cdot 6 \mathrm{H}_{2} \mathrm{O}$ was dissolved in $50 \mathrm{ml}$ of deionized water containing $1 \mathrm{~g}$ of functionalized CNTs. This was then ultrasonicated for $10 \mathrm{~min}$ and magnetically stirred for $15 \mathrm{~min}$ at $80{ }^{\circ} \mathrm{C}$. The addition of $1.1 \mathrm{~g}$ of $\mathrm{NaOH}$ to the mixture and stirring for $30 \mathrm{~min}$ completed the precipitation of $\mathrm{Ni}(\mathrm{OH})_{2} / \mathrm{CNTs}$ nanocomposite. The obtained black mixture was filtered, washed with absolute ethanol and deionized water, dried at $120{ }^{\circ} \mathrm{C}$ for $24 \mathrm{~h}$, and finally calcinated at $300{ }^{\circ} \mathrm{C}$ for $2 \mathrm{~h}$ in static air.

\section{Methods of analysis}

To determine the optimum calcination temperature of $\mathrm{NiO} / \mathrm{CNT}$ nanocomposite powder, simultaneous thermal analysis (STA 1500) was applied in a static air atmospheric $\left(10{ }^{\circ} \mathrm{C} \mathrm{min}{ }^{-1}\right)$. The residual concentration of $\mathrm{Pb}^{2+}$ ions in aqueous media was analysed with the aid of Buck Scientifics 210 VGP flame atomic adsorption spectroscopy. The crystallinity of samples was determined using Xpertpr Pananalytical X-ray diffraction apparatus (Holland) with $\mathrm{Cu}\left(\mathrm{K}_{\alpha}\right)$ source and wavelength of $\lambda=1.5405 \AA$. The morphology of powders was recorded using Field Emission Scanning Electron Microscopy on a Mira3-XMU system. The BET specific surface area and porosity were determined using nitrogen adsorption-desorption porosimetry $(77 \mathrm{~K})$ by a porosimeter (Bel Japan, Inc.).

\section{Adsorption studies}

In this section, $1000 \mathrm{ppm}$ of $\mathrm{Pb}^{2+}$ stock solution was initially provided through dissolving the desired volume of $\left(\mathrm{Pb}\left(\mathrm{NO}_{3}\right)_{2}\right)$ in deionized water; the corresponding concentrations were then obtained from the dilution of the stock solution. For batch adsorption experiments, $0.1 \mathrm{~g}$ of $\mathrm{NiO} / \mathrm{CNT}$ was added to $50 \mathrm{ml}$ of $20 \mathrm{ppm}$ solution of $\mathrm{Pb}^{2+}$ and then stirred. After adsorption, the nanocomposite was 
Fig. 1 STA curves of $\mathrm{Ni}(\mathrm{OH})_{2} /$ CNT in air

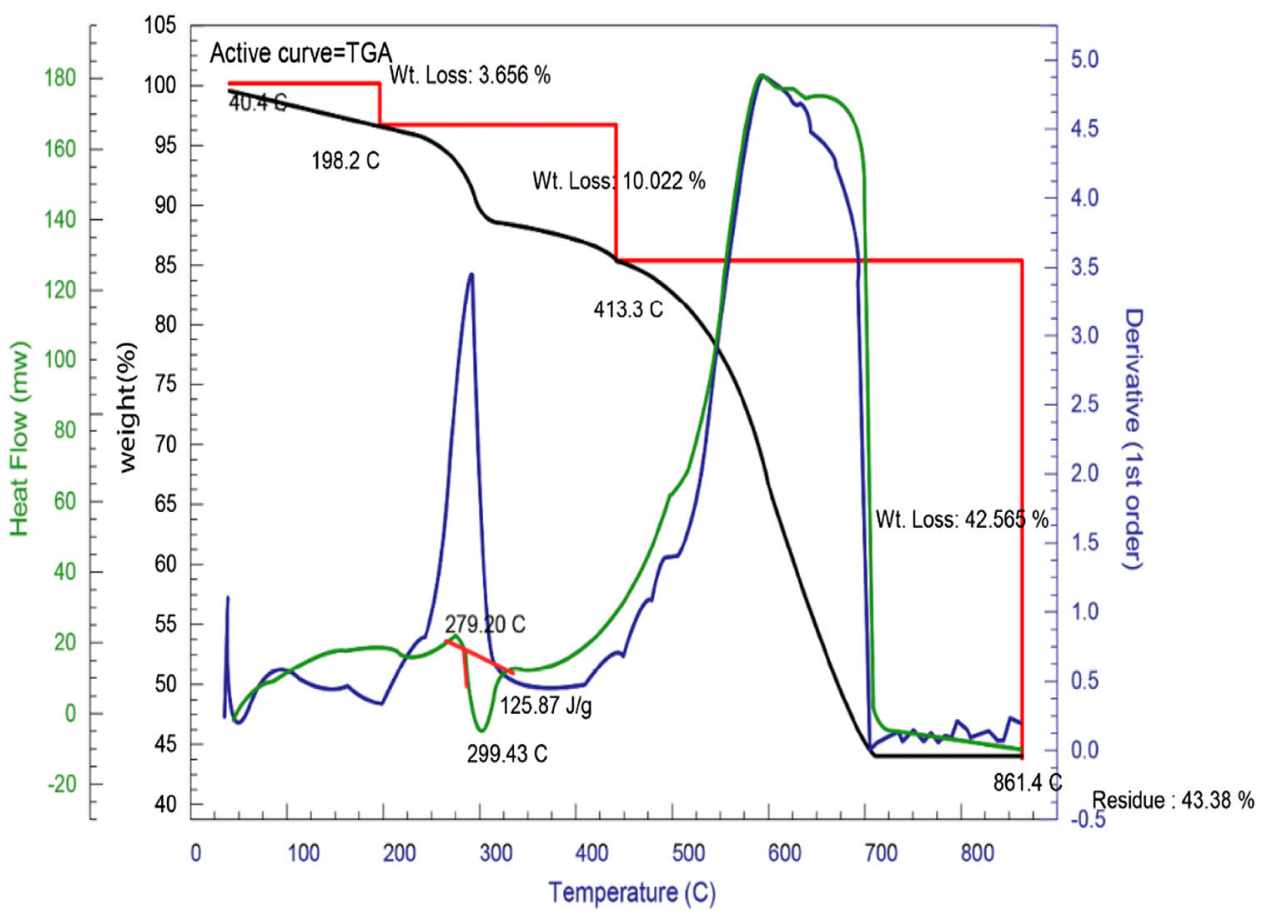

taken from the solution and the residual $\mathrm{Pb}^{2+}$ concentration was measured using flame atomic adsorption spectroscopy. The effects of the different parameters namely $\mathrm{pH}$, initial $\mathrm{Pb}^{2+}$ concentration, adsorbent dosage, and contact time on the amount of adsorption were investigated through the removal percentage $(R)$ of $\mathrm{Pb}^{2+}$ by the equation mentioned below:

$\% R=\frac{C_{0}-C_{\mathrm{e}}}{C_{0}} \times 100$,

here, $C_{0}$ and $C_{\mathrm{e}}$ are the initial and equilibrium concentrations of $\mathrm{Pb}^{2+}\left(\mathrm{mg} \mathrm{L}^{-1}\right)$.

\section{Result and discussion}

\section{$\mathrm{NiO} / \mathrm{CNT}$ characterization}

To study the temperature-dependent behaviour of nanocomposite, STA was performed on $\mathrm{Ni}(\mathrm{OH})_{2} / \mathrm{CNT}$ synthesized precursor in static air. According to the obtained spectra (Fig. 1), in the temperature range of 40$800{ }^{\circ} \mathrm{C}$, three endothermic reactions occur in $\mathrm{Ni}(\mathrm{OH})_{2} /$ CNT. In the range of $40-400{ }^{\circ} \mathrm{C}$, two stages of weight loss in the sample are observed. These can be attributed to two reactions in the initial stage at $40-200{ }^{\circ} \mathrm{C}$, attributing to
Fig. 2 FESEM of a pure $\mathrm{NiO}$ and $\mathbf{b} \mathrm{NiO} / \mathrm{CNT}$ nanocomposite
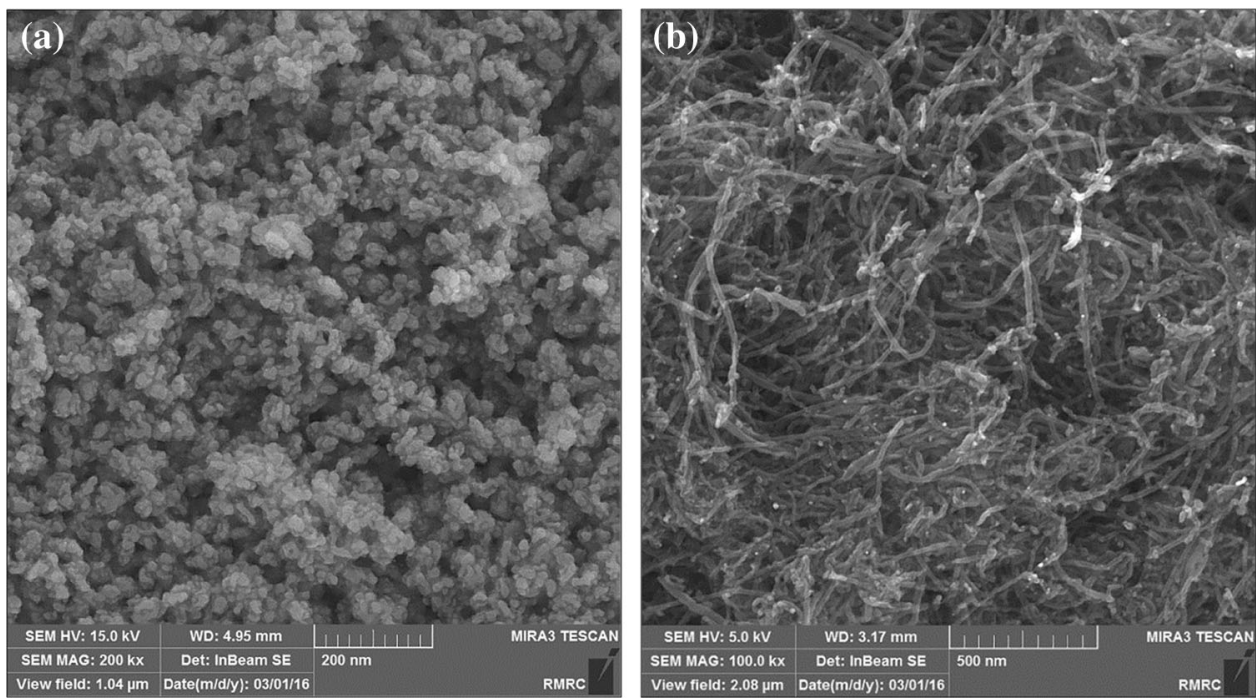


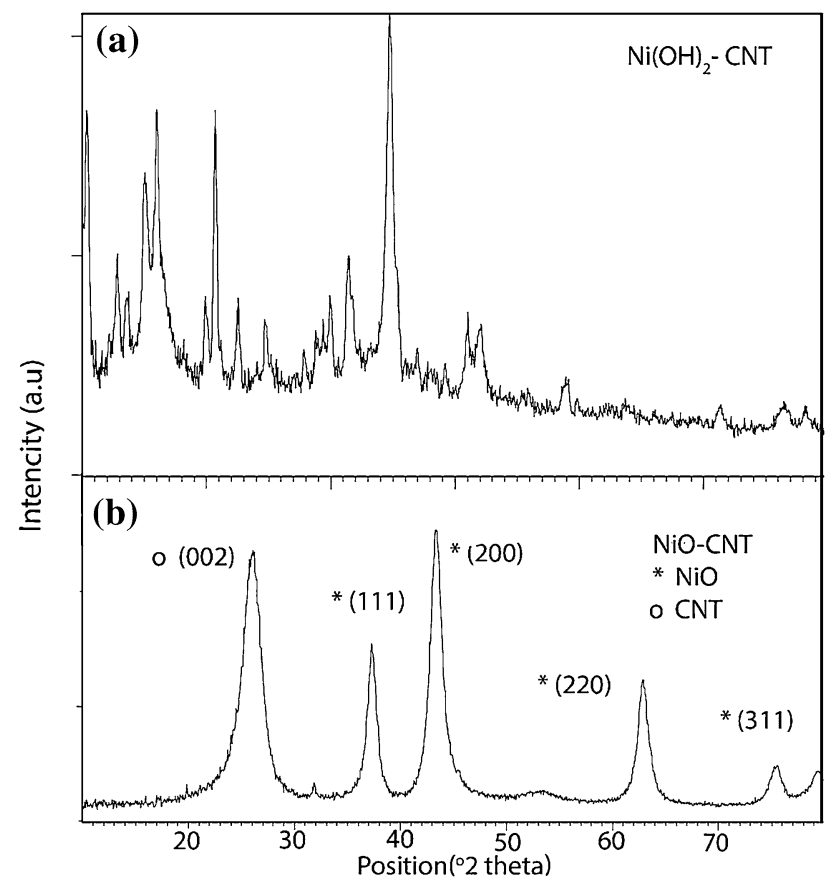

Fig. 3 XRD pattern of a $\mathrm{Ni}(\mathrm{OH})_{2} / \mathrm{CNT}$ and b $\mathrm{NiO} / \mathrm{CNT}$ nanocomposite

surface moisture evaporation and the second one at 200$400{ }^{\circ} \mathrm{C}$ is the result of water release and the formation of $\mathrm{NiO}$ chemical structure with the following reactions:

$\mathrm{Ni}(\mathrm{OH})_{2} \cdot 6 \mathrm{H}_{2} \mathrm{O} \rightarrow \mathrm{Ni}(\mathrm{OH})_{2}+6 \mathrm{H}_{2} \mathrm{O}$,

$\mathrm{Ni}(\mathrm{OH})_{2} \rightarrow \mathrm{NiO}+\mathrm{H}_{2} \mathrm{O}$.

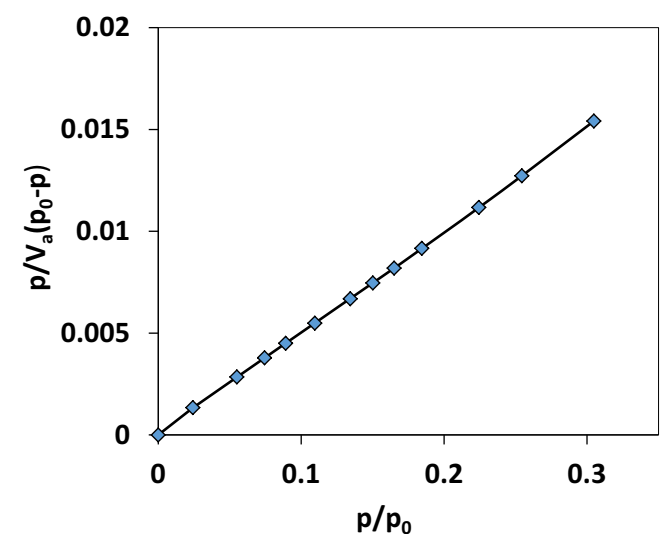

Fig. 4 BET plot of NiO/CNT nanocomposite

The slow decrease in weight at a temperature above $300{ }^{\circ} \mathrm{C}$ is related to the removal of small amounts of hydroxyl-groups remaining during the development of the $\mathrm{NiO}$ phase [27].

The weight percentage of the sample at $400{ }^{\circ} \mathrm{C}$ was $86 \%$, which is related to the $\mathrm{NiO} / \mathrm{CNT}$ nanocomposite. At $800{ }^{\circ} \mathrm{C}$, the weight percentage of the sample reached $43 \%$, due to the oxidation of CNTs into $\mathrm{CO}_{2}$ [28]. Following the specifications of STA, $300{ }^{\circ} \mathrm{C}$ was considered as the reaction temperature in the study.

The morphologies of $\mathrm{NiO} / \mathrm{CNT}$ and pure $\mathrm{NiO}$ were analysed using FESEM images, as shown in Fig. 2. It can be seen in Fig. 2a that $\mathrm{NiO}$ nano-crystallites are aggregated, forming clusters with larger grains. The formation of this agglomerated structure has unfavourable impacts on
Fig. 5 a Effect of $\mathrm{pH}$, b contact time, $\mathbf{c}$ adsorbent mass and d initial concentration on $\mathrm{Pb}^{2+}$ removal by $\mathrm{NiO} / \mathrm{CNT}$ nanocomposite
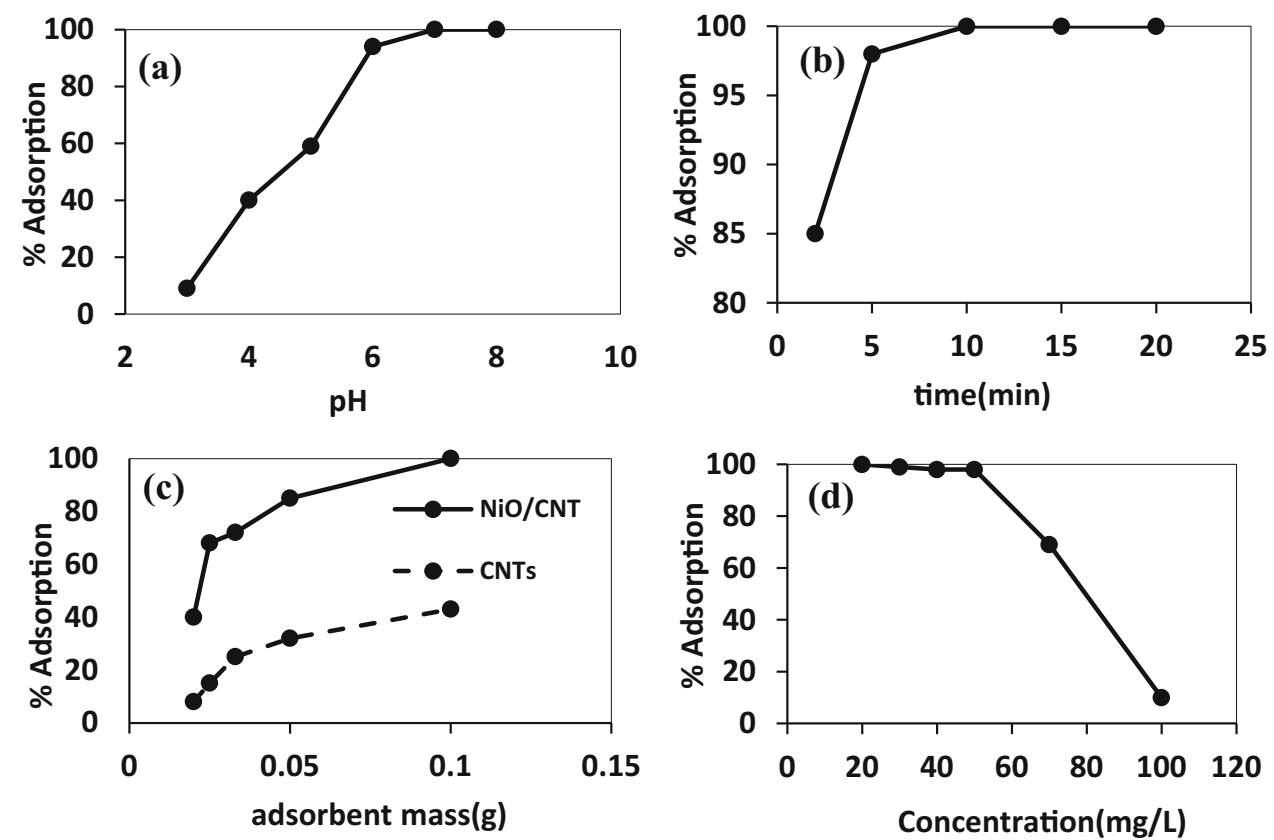
Fig. 6 a Langmuir, b Freundlich adsorption isotherm, c pseudo-first-order, d pseudo-second-order kinetic models and e Van't Hoff plot for $\mathrm{Pb}^{2+}$ removal on $\mathrm{NiO} / \mathrm{CNT}$ nanocomposite
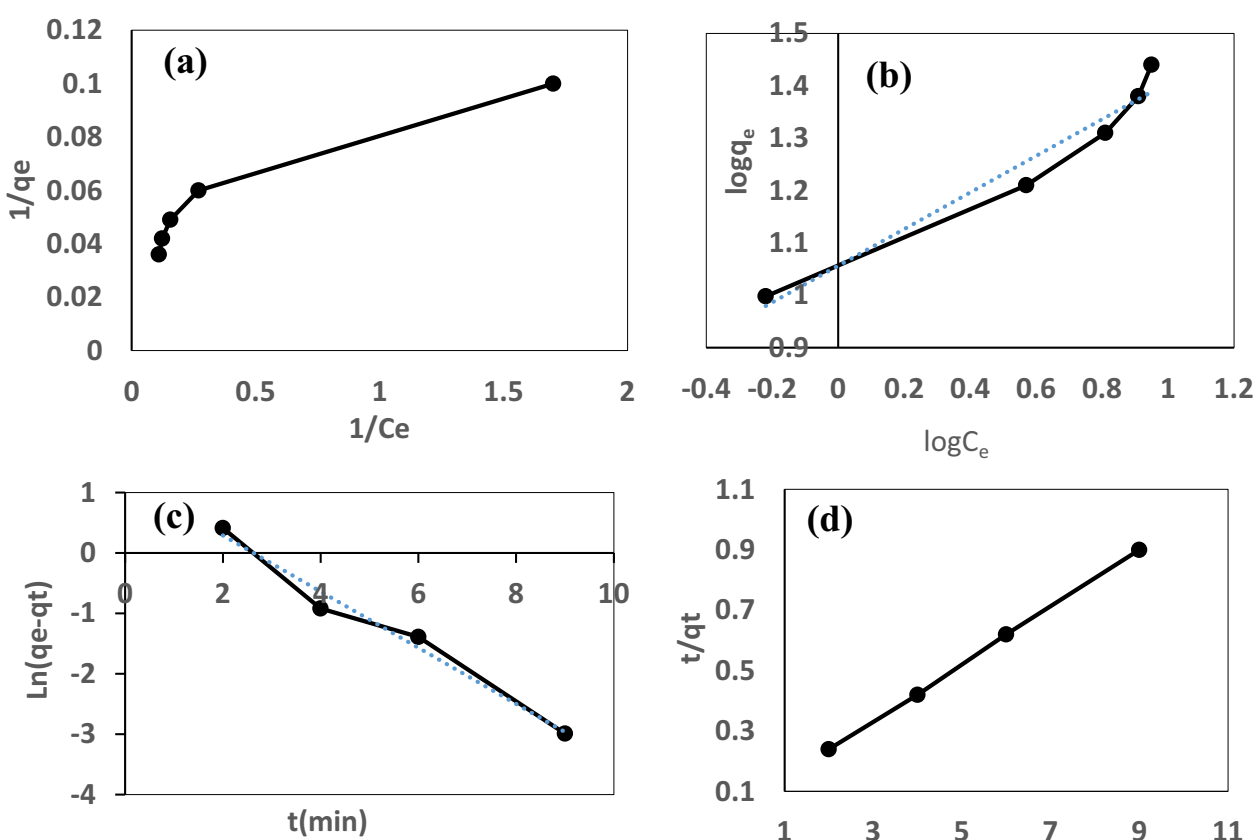

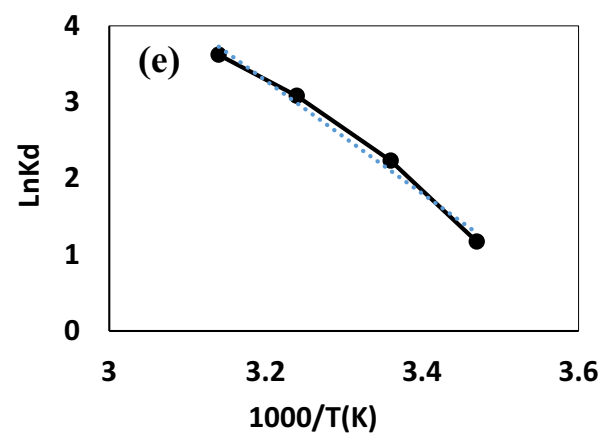

the physical and chemical features of nanoparticles. The utilization of CNTs as the support material for the growth of nanoparticles reduces the agglomeration and changes the powder morphology from a cluster-like to a filamentous structure (Fig. 2b). It is observed that the nanoparticles on the surface of CNTs possess smaller dimensions in comparison with pure $\mathrm{NiO}$ nanoparticles [27].

Figure 3 indicates the X-ray diffraction pattern of $\mathrm{Ni}(\mathrm{OH})_{2} / \mathrm{CNT}$ and $\mathrm{NiO} / \mathrm{CNT}$ nanocomposites. Characteristic peaks at $2 \theta=37.3^{\circ}, 43.4^{\circ}, 62.9^{\circ}$ and $75.4^{\circ}$ are assigned to (111), (200), (220), and (311) crystallographic orientations in $\mathrm{NiO}$ nanoparticles, respectively (Fig. 3a), the strong diffraction peak at $2 \theta=26^{\circ}$ reflected from (002) lattice plane in CNTs [29]. The peaks of $\mathrm{Ni}(\mathrm{OH})_{2} /$ CNT cannot be seen at $\mathrm{NiO} / \mathrm{CNT}$, which is due to the crystallization and change in the structure of crystal. The size of NiO/CNT nanoparticles was calculated using the Scherrer equation $D=\frac{k \lambda}{\beta \cos \theta}$. The main reflection peak of the XRD pattern at $2 \theta=43^{\circ}$ can be attributed to (200) plane. The size of NiO/CNT nano-crystallites was $18.5 \mathrm{~nm}$.
$\mathrm{N}_{2}$ adsorption-desorption isotherms was utilized to assess the specific surface area, mean pore diameter and the total volume of NiO/CNT nanocomposite. The specific surface area of NiO/CNT nanocomposite was measured by the Brunauer-Emmett-Teller (BET) method (Fig. 4). The specific surface area, mean pore diameter and the total pore volume of $\mathrm{NiO} / \mathrm{CNT}$ nanocomposite were determined to be $90 \mathrm{~m}^{2} \mathrm{~g}^{-1}$, $4.16 \mathrm{~nm}$ and $9.26 \times 10^{-2} \mathrm{~cm}^{3} \mathrm{~g}^{-1}$, respectively.

\section{Effect of pH}

The $\mathrm{pH}$ is among the most remarkable parameters that should be controlled in metal ions adsorption process of aqueous solutions. To evaluate the effect of $\mathrm{pH}$, the initial $\mathrm{pH}$ varied from 3 to 8 in the solution. It was observed (Fig. 5a) that the rate of removal of $\mathrm{Pb}^{2+}$ increased rapidly, from about $9-94 \%$ as $\mathrm{pH}$ increased from 3 to 6 , and then remained constant following the increase of $\mathrm{pH}$ value from 7 to 8 . Based on the authors' best knowledge, lead species are available in $\mathrm{Pb}^{2+}$ and $\mathrm{Pb}(\mathrm{OH})^{+}$forms at $\mathrm{pH} 3-8$ [30]. 
Table 1 Langmuir, Freunlich parameters and correlation coefficients of $\mathrm{Pb}^{2+}$ adsorption onto $\mathrm{NiO} / \mathrm{CNT}$

\begin{tabular}{|c|c|c|c|c|c|}
\hline \multirow{2}{*}{$\begin{array}{l}\text { Langmuir } \\
q_{\mathrm{m}}\left(\mathrm{mg} \mathrm{g}^{-1}\right)\end{array}$} & \multicolumn{2}{|c|}{$\frac{1}{q_{\mathrm{e}}}=\left(\frac{1}{q_{\mathrm{m}} K_{L}}\right)+\left(\frac{1}{C_{\mathrm{e}}}\right)+\frac{1}{q_{\mathrm{m}}}$} & \multirow{2}{*}{$\begin{array}{l}\text { Freundlich } \\
K_{\mathrm{F}}\left(\mathrm{L} \mathrm{mg}^{-1}\right)\end{array}$} & \multicolumn{2}{|c|}{$\log q_{\mathrm{e}}=\log K_{\mathrm{F}}+\frac{1}{n} \log C_{\mathrm{e}}$} \\
\hline & $\overline{K_{\mathrm{L}}\left(\mathrm{L} \mathrm{mg}^{-1}\right)}$ & $R^{2}$ & & $\overline{1 / n}$ & $R^{2}$ \\
\hline 24.63 & 1.14 & 0.9279 & 11.39 & 0.3493 & 0.9502 \\
\hline
\end{tabular}

Table 2 The equilibrium capacities of $\mathrm{Pb}$ (II) on various adsorbents

\begin{tabular}{|c|c|c|}
\hline Adsorbents & $q_{\max }\left(\mathrm{mg} \mathrm{g}^{-1}\right)$ & References \\
\hline MWCNTs & 1 & {$[35]$} \\
\hline MWCNTs & 4 & {$[36]$} \\
\hline Activated carbon & 13.05 & [37] \\
\hline MWCNTs & 15.6 & {$[35]$} \\
\hline Oxidized MWCNTs & 2.06 & {$[38]$} \\
\hline Oxidized N-doped MWCNTs & 29 & [39] \\
\hline MWCNT-f & 14.56 & {$[40]$} \\
\hline Tiol/CNT & 65.52 & [41] \\
\hline $\mathrm{SiO}_{2} / \mathrm{MWCNT}$ & 13 & {$[42]$} \\
\hline Iron oxid/MWCNT & 12 & {$[43]$} \\
\hline $\mathrm{Al}_{2} \mathrm{O}_{3} / \mathrm{CNTs}$ & 67.5 & [44] \\
\hline PAAM/MWCNTs & 29.71 & {$[45]$} \\
\hline Zeolites: chabazite & 6 & {$[46]$} \\
\hline $\mathrm{NiO} / \mathrm{CNTs}$ & 24.63 & This study \\
\hline
\end{tabular}

When the $\mathrm{pH}$ value is low $(<6)$, the predominant lead specie is $\mathrm{Pb}^{2+}$ and $\mathrm{Pb}^{2+}$ is removed by sorption reaction. Therefore, the lower adsorption percentage of $\mathrm{Pb}^{2+}$ on $\mathrm{NiO} / \mathrm{CNT}$ at lower $\mathrm{pH}$ values partly depends on the competition between $\mathrm{H}^{+}$and $\mathrm{Pb}^{2+}$ on the surface sites $\mathrm{Pb}^{2+}$ removal rate, which is maximized in $\mathrm{pH}$ values 6 to 8 and then remains constant. In this range, the main species are $\mathrm{Pb}^{2+}$ and $\mathrm{Pb}(\mathrm{OH})^{+}$; hence, $\mathrm{Pb}^{2+}$ removal is regulated by the sorption of $\mathrm{Pb}^{2+}$ and $\mathrm{Pb}(\mathrm{OH})^{+}$. According to the results of the current study, to eliminate $\mathrm{Pb}^{2+}$ from the solution by $\mathrm{NiO} / \mathrm{CNT}, \mathrm{pH} 7$ is the most optimum value for the employed system.

\section{Effect of contact time}

The contact time and its effect on $\mathrm{Pb}^{2+}$ elimination rate using NiO/CNT is depicted in Fig. 5b. The highest amount of adsorption approximately $100 \%$, was achieved after $10 \mathrm{~min}$ of adsorption at $\mathrm{pH}$ 7. Therefore, a period of 10 min was considered as the optimum contact time for $\mathrm{Pb}^{2+}$ adsorption on the $\mathrm{NiO} / \mathrm{CNT}$ nanocomposite.

\section{Effect of adsorbent mass}

Figure $5 c$ illustrates the effect of adsorbent mass on the removal rate for a $20 \mathrm{ppm}$ solution of $\mathrm{Pb}^{2+}$ by $\mathrm{NiO} / \mathrm{CNT}$ nanocomposite and CNTs. In both adsorbents, the percentage of adsorbed lead increased as the mass of adsorbent was increased over the range of $0.02-0.1 \mathrm{~g}$. A removal rate of approximately $100 \%$ was obtained when $0.1 \mathrm{~g}$ of $\mathrm{NiO} / \mathrm{CNT}$ nanocomposite was drowned in $50 \mathrm{~mL}$ of the $20 \mathrm{ppm}^{2+} \mathrm{Pb}^{2+}$ solution, compared to $43 \%$ removal when $0.1 \mathrm{~g}$ of CNTs was used. Based on the given results, it is obvious that the mechanism of nanocomposite adsorption towards $\mathrm{Pb}^{2+}$ may be attributed to three factors: the van der Waals interaction between the hexagonally arrayed carbon atoms in the graphite sheets of the CNTs and the positively charged lead ions, the electrostatic attraction between the negatively charged adsorbent surface of the CNT and $\mathrm{Pb}^{2+}$ cations, and the electrostatic attraction between $\mathrm{Pb}^{2+}$ and the electron pairs on the oxygen atoms of nickel oxide [30].

\section{Effect of $\mathrm{Pb}^{2+}$ initial concentration}

Figure $5 \mathrm{~d}$ indicates the variation in removal rate in the initial concentration of $\mathrm{Pb}^{2+}$. It is evident that the initial concentration increase of $\mathrm{Pb}^{2+}$ from 20 to $100 \mathrm{ppm}$ reduces the removal efficiency from almost 100-10\%. At lower initial concentrations of $\mathrm{Pb}^{2+}$, an adequate number of active sites are available for adsorption, leading to a higher adsorption capacity. It is also noteworthy that at higher initial concentrations, the number of metal ions is higher compared with active adsorption sites; therefore, the removal efficiency decreases [31].

\section{Adsorption isotherms}

Adsorption isotherms represent the amount of adsorbed metal ion per unit mass of the adsorbent. Among all the isotherm models, the Langmuir and Freundlich models are the most popular ones describing adsorption in these systems [32-34]. The equilibrium adsorption capacity $\left(q_{\mathrm{e}}\right)$ is calculated using:

$q_{\mathrm{e}}=\frac{C_{0}-C_{\mathrm{e}}}{m} V$,

here $q_{\mathrm{e}}$ is the adsorbed $\mathrm{Pb}^{2+}$ amount $\left(\mathrm{mg} \mathrm{g}^{-1}\right)$, $\mathrm{m}$ is the composite mass $(\mathrm{g})$, and $V$ is the solution volume (L).

Figure 6a, b, respectively, illustrate Langmuir and Freundlich isotherms for $\mathrm{Pb}^{2+}$ adsorption on $\mathrm{NiO} / \mathrm{CNT}$ nanocomposite with the obtained parameters summarized in Table 1. According to the data shown in Table 1, both the Langmuir and Freundlich models are appropriate for 
Table 3 Adsorption kinetic parameters of $\mathrm{Pb}^{2+}$ adsorption onto NiO/CNT

\begin{tabular}{|c|c|c|c|c|c|c|}
\hline \multicolumn{3}{|c|}{ Psedo-first-order $\operatorname{Ln}\left(q_{\mathrm{e}}-q_{\mathrm{t}}\right)=\mathrm{Lnq}_{\mathrm{e}}-k_{1} t$} & \multicolumn{3}{|c|}{ Psedo-second-order $\frac{t}{q_{\mathrm{t}}}=\frac{1}{k_{2} q_{\mathrm{e}}^{2}}+\frac{1}{q_{\mathrm{e}}} t$} & \multirow{2}{*}{$\begin{array}{l}\text { Experimental data } \\
q_{\mathrm{e}, \exp }\left(\mathrm{mg} \mathrm{g}^{-1}\right)\end{array}$} \\
\hline$\overline{k_{1}\left(\min ^{-1}\right)}$ & $q_{\mathrm{e}, \mathrm{cal}}\left(\mathrm{g} \mathrm{mg}^{-1} \min ^{-1}\right)$ & $R^{2}$ & $\overline{k_{2}\left(\mathrm{~g} \mathrm{mg}^{-1} \min ^{-1}\right)}$ & $q_{\mathrm{e}, \mathrm{cal}}\left(\mathrm{mg} \mathrm{g}^{-1}\right)$ & $R^{2}$ & \\
\hline 0.46 & 16.54 & 0.9787 & 0.189 & 10.55 & 0.9997 & 10 \\
\hline
\end{tabular}

Table 4 Values of thermodynamic parameters of adsorption of $\mathrm{Pb}^{2+}$ onto $\mathrm{NiO} /$ CNT

\begin{tabular}{|c|c|c|c|c|c|}
\hline \multicolumn{2}{|c|}{$\operatorname{Ln} K_{\mathrm{d}}=\frac{\Delta S^{\circ}}{R}-\frac{\Delta H^{\circ}}{R T}$} & \multicolumn{4}{|c|}{$\Delta G^{\circ}$ (temperature, $\left.\mathrm{K}\right)$} \\
\hline$\Delta S^{\circ}$ & $\Delta H^{\circ}$ & $\Delta G^{\circ}=-R$ & & & $K_{\mathrm{d}}=\frac{q_{\mathrm{e}}}{C_{\mathrm{e}}}$ \\
\hline 224.26 & 61.55 & $2.80(288)$ & $-5.52(298)$ & $-7.89(308)$ & $-9.57(318)$ \\
\hline
\end{tabular}

interpreting the obtained experimental data; however, the Freundlich model, with a higher correlation coefficient $\left(R^{2}\right)$, showed higher compatibility with the data, compared with the Langmuir model.

To get the synthesized absorbent efficiency approved, its maximum amount of absorption was compared with other adsorbents. As shown in Table 2, the maximum absorption capacity obtained in this study is significant compared to other adsorbents [35-46], which indicates the efficiency of the synthetic adsorbent.

\section{Adsorption kinetics}

One of the most important features of designing an adsorption system is the prediction of the adsorption rate, i.e., how fast the adsorption is taking place, which is controlled by adsorption kinetics. The adsorption kinetics depends on the adsorbent physical and chemical properties; it also affects the adsorption mechanism. To evaluate the adsorption mechanism, adsorption kinetic constants, Lagergren pseudo first-order and Ho, pseudo second-order rate equations can be used [47].

The obtained results are summarized in Fig. $6 \mathrm{c}, \mathrm{d}$, and Table 3. According to Table 3, the pseudo second-order model, with higher values of correlation coefficient $\left(R^{2}\right)$ and closer values of calculated adsorption capacity $\left(q_{\mathrm{e}, \mathrm{cal}}\right)$ to experimental one $\left(q_{\mathrm{e}, \exp }\right)$ is a better model to describe the adsorption capacity of ions on $\mathrm{NiO} / \mathrm{CNT}$ nanocomposite. This indicates that the adsorption of $\mathrm{Pb}^{2+}$ onto NiO/CNT may be the chemisorption involving valence forces through the exchange or sharing of electrons between adsorbate and adsorbent [48].

\section{Adsorption thermodynamics}

Another feature of any adsorption process with high significance is the determination of thermodynamic parameters, including changes in Gibbs free energy $\left(\Delta G^{\circ}\right.$, $\left.\mathrm{KJ} \mathrm{mol}^{-1}\right)$, enthalpy $\left(\Delta H^{\circ}, \mathrm{KJ} \mathrm{mol}^{-1}\right)$, and entropy $\left(\Delta S^{\circ}\right.$,
$\mathrm{J} \mathrm{mol}^{-1} \mathrm{~K}^{-1}$ ). Adsorption thermodynamics were evaluated at different temperatures $(288,298,308$, and $318 \mathrm{~K})$. The results are depicted in Fig. 6e. To measure the thermodynamic parameters and $K_{\mathrm{d}}$ values, Van't Hoff equation was applied [49].

The results of calculation are shown in Table 4. The negative values of $\Delta G^{\circ}$ indicate that the adsorption was a spontaneous reaction. The $\Delta H^{\circ}$ and $\Delta S^{\circ}$ positive values are attributed to the endothermic nature of adsorption and the increase in the randomness at the solid/liquid interface during the adsorption of $\mathrm{Pb}^{2+}$ on $\mathrm{NiO} / \mathrm{CNT}$ nanocomposite, respectively.

\section{Conclusion}

In this study, NiO/CNT nanocomposite was utilized as an adsorbent to remove $\mathrm{Pb}^{2+}$ from an aqueous solution. The $\mathrm{NiO} / \mathrm{CNT}$ nanocomposite powder was prepared using direct coprecipitation process in the aqueous media. The results indicate that the optimum efficiency for $\mathrm{Pb}^{2+}$ removal is achieved under experimental conditions of $\mathrm{pH}$ 7 , contact time of $10 \mathrm{~min}$, and the initial $\mathrm{Pb}^{2+}$ concentration of $20 \mathrm{ppm}$. Moreover, increasing the initial concentration of $\mathrm{Pb}^{2+}$ and reducing the adsorbent dosage diminishes the removal efficiency. Therefore, NiO/CNT nanocomposite can be considered as a useful adsorbent for the elimination of aqueous solutions from $\mathrm{Pb}^{2+}$. In addition, results obtained from $\mathrm{Pb}^{2+}$ adsorption on $\mathrm{NiO} / \mathrm{CNT}$ nanocomposite follow the pseudo second-order rate equation and Freundlich isotherm.

Open Access This article is distributed under the terms of the Creative Commons Attribution 4.0 International License (http://crea tivecommons.org/licenses/by/4.0/), which permits unrestricted use, distribution, and reproduction in any medium, provided you give appropriate credit to the original author(s) and the source, provide a link to the Creative Commons license, and indicate if changes were made. 


\section{References}

1. Bedelean, H., Maicaneanu, A., Burca, S., Stanca, M.: Removal of heavy metal ions from wastewaters using natural clays. J. Clay Miner. 44, 487-495 (2009)

2. Chand, P., Pakade, Y.B.: Synthesis and characterization of hydroxyapatite nanoparticles impregnated on apple pomace to enhanced adsorption of $\mathrm{Pb}(\mathrm{II}), \mathrm{Cd}(\mathrm{II})$ and $\mathrm{Ni}$ (II) ions from aqueous solution. Environ. Sci. Pollut. Res. 22, 10919-10929 (2015)

3. Shafaei, A., Ashtiani, F.Z., Kaghazchi, T.: Equilibrium studies of the sorption of $\mathrm{Hg}$ (II) ions onto chitosan. Chem. Eng. J. 133(1-3), 311-316 (2007)

4. Kumar, R., Singh, R.K., Dubey, P.K., Singh, D.P., Yadav, R.M., Tiwari, R.S.: Freestanding 3D graphene-nickel encapsulated nitrogen-rich aligned bamboo like carbon nanotubes for highperformance supercapacitors with robust cycle stability. Adv. Mater. Interfaces 2, 1500191 (2015)

5. Kumar, R., Singh, R.K., Singh, D.P., Vaz, A.R., Yadav, R.R., Rout, C.S., Moshkalev, S.A.: Synthesis of self-assembled and hierarchical palladium-CNTs-reduced graphene oxide composites for enhanced field emission properties. Mater. Des. 122, 110-117 (2017)

6. Kumar, R., Singh, R.K., Dubey, P.K., Singh, D.P., Yadav, R.M.: Self-assembled Hierarchical formation of conjugated 3D cobalt oxide nanobeads-CNTs-graphene nanostructure using microwave for high performance supercapacitor electrode. ACS Appl. Mater. Interfaces 7, 15042-15051 (2015)

7. Zare, K., Gupta, V.K., Moradi, O., Makhlouf, A.S.H., Sillanpää, M., Nadagouda, M.N., Sadegh, H., Shahryari-ghoshekandi, R., Pal, A., Wang, Z., Tyagi, T., Kazemi, M.: A comparative study on the basis of adsorption capacity between CNTs and activated carbon as adsorbents for removal of noxious synthetic dyes: a review. J. Nanostruct. Chem. 5(2), 227-236 (2015)

8. Moradi, O., Fakhri, A., Adami, S., Adami, S.: Isotherm, thermodynamic, kinetics, and adsorption mechanism studies of Ethidium bromide by single-walled carbon nanotube and carboxylate group functionalized single-walled carbon nanotube. J. Colloid Interface Sci. 395, 224-229 (2013)

9. Abd El Fatah, Ossman, M.E.: Removal of heavy metal by nickel oxide nano powder. Int. J. Environ. Res. 8(3), 741-750 (2014)

10. Coston, J.A., Fuller, C.C., Davis, J.A.: $\mathrm{Pb}^{2+}$ and $\mathrm{Zn}^{2+}$ adsorption by a natural aluminum-and iron-bearing surface coating on an aquifer sand. Geochim. Cosmochim. Acta 59, 3535-3547 (1995)

11. Agrawal, A., Sahu, K.K.: Kinetic and isotherm studies of cadmium adsorption on manganese nodule residue. J. Hazard. Mater. 137, 915-924 (2006)

12. Srivastava, N.K., Jha, M.K., Sreekrishnan, T.R.: Removal of $\mathrm{Cr}(\mathrm{VI})$ from waste water using $\mathrm{NiO}$ nanoparticles. Int. Sci. Environ. Technol. 3(2), 395-402 (2014)

13. Awasthi, S., Awasthi, K., Kumar, R., Srivastava, O.N.: Functionalization effects on the electrical properties of multi-walled carbon nanotube-polyacrylamide composites. J. Nanosci. Nanotechnol. 9, 5455-5460 (2009)

14. Kumar, R., Singh, R.K., Ghosh, A.K., Sen, R., Srivastava, S.K., Tiwari, R.S., Srivastava, O.N.: Synthesis of coal-derived singlewalled carbon nanotube from coal by varying the ratio of $\mathrm{Zr} / \mathrm{Ni}$ as bimetallic catalyst. J. Nanopart. Res. 15, 1406 (2013)

15. Kumar, R., Singh, R.K., Singh, D.P.: Natural and waste hydrocarbon precursors for the synthesis of carbon based nanomaterials: graphene and CNTs. Renew. Sustain. Energy Rev. 58, 976-1006 (2016)

16. Li, Y.H., Di, Z., Ding, J., Wu, D., Luan, Z., Zhu, Y.: Adsorption thermodynamic, kinetic and desorption studies of $\mathrm{Pb}^{2+}$ on carbon nanotubes. Water Res. 39, 605-609 (2005)
17. Taleshi, F., Hosseini, A.A.: Synthesis of uniform $\mathrm{MgO} / \mathrm{CNT}$ nanorods by precipitation method. J. Nanostruct. Chem. 3(1), 1-5 (2012)

18. Jiang, S., Storr Handberg, E., Liu, F., Liao, Y., Wang, H., Li, Z., Song, S.: Effect of doping the nitrogen into carbon nanotubes on the activity of $\mathrm{NiO}$ catalysts for the oxidation removal of toluene. Appl. Catal. B 160-161, 716-721 (2014)

19. Songa, S., Meng, A., Jiang, S., Cheng, B., Jiang, C.: Construction of $\mathrm{Z}$-scheme $\mathrm{Ag}_{2} \mathrm{CO}_{3} / \mathrm{N}$-doped graphene photocatalysts with enhanced visible-light photocatalytic activity by tuning the nitrogen species. Appl. Surf. Sci. 396, 1368-1374 (2017)

20. Taleshi, F., Porkia, M., Shakeri Chenari, I., Pahlavan, A., Ahmadi Tarsi, M., Zabihi, F., Dehghan-niarostami, N.: Morphology of $\mathrm{CuFe}_{2} \mathrm{O}_{4} / \mathrm{CNT}$ composites prepared by precipitation, plastics, rubber and composites. Macromol. Eng. 43, 240-244 (2014)

21. Han, W.Q., Zettl, A.: Coating single-walled carbon nanotubes with tin oxide. Nano Lett. 3, 681-683 (2003)

22. Mallick, P., Chandanarath Biswal, R., Mishra, N.C.: Structural and magnetic properties of $\mathrm{Fe}$ doped NiO. Indian J. Phys. 83, 517-523 (2009)

23. Mallick, P., Sahoo, C.S., Mishra, N.C.: Structural and optical characterization of $\mathrm{NiO}$ nanoparticles synthesized by sol-gel route. AIP Conf. Proc. 1461, 229-232 (2012)

24. Takami, S., Hayakawa, R., Wakayama, Y., Chikyow, T.: Continuous hydrothermal synthesis of nickel oxide nanoplates and their use as nanoinks for p-type channel material in a bottom-gate field-effect transistor. Nanotechnology 21, 134009 (2010)

25. Yudin, A., Shatrova, N., Khaydarov, B., Kuznetsov, D., Dzidziguri, E., Issi, J.P.: Synthesis of hollow nanostructured nickel oxide microspheres by ultrasonic spray atomization. J. Aerosol Sci. 98, 30-40 (2016)

26. Chakrabarty, S., Chatterjee, K.: Synthesis and characterization of nanodimensional $\mathrm{NiO}$ semiconductor. J. Phys. Sci. 13, 245-250 (2008)

27. Lin, P., She, Q., Hong, B., Liu, X., Shi, Y., Shi, Z., Zheng, M., Donga, Q.: The nickel oxide/CNT composites with high capacitance for supercapacitor. J. Electrochem. Soc. 157(7), A818A823 (2010)

28. Kumar, R., Singh, R.K., Vaz, A.R., Savu, R., Moshkalev, S.A.: Self-assembled and one-step synthesis of interconnected 3D network of $\mathrm{Fe}_{3} \mathrm{O}_{4}$ /reduced graphene oxide nanosheets hybrid for high-performance supercapacitor electrode. Appl. Mater. Interfaces 9, 8880-8890 (2017)

29. Taleshi, F.: A new strategy for increasing the yield of carbon nanotubes by the CVD method. Fuller. Nanotubes Carbon Nanostruct. 22, 921-927 (2014)

30. Gupta, V.K., Agarwal, S., Saleh, T.A.: Synthesis and characterization of alumina-coated carbon nanotubes and their application for lead removal. J. Hazard. Mater. 185, 17-23 (2011)

31. Rao, M.M., Ramesh, A., Rao, G.P.C., Seshaiah, K.: Removal of copper and cadmium from the aqueous solutions by activated carbon derived from Ceiba pentandra hulls. J. Hazard. Mater. B 129, 123-129 (2006)

32. Tahermansouri, H., Dehghan, Z., Kiani, F.: Phenol adsorption from aqueous solutions by functionalized multiwalled carbon nanotubes with a pyrazoline derivative in the presence of ultrasound. RSC Adv. 5, 44263-44273 (2015)

33. Langmuir, I.: The adsorption of gases on plane surfaces of glass, mica and platinum. J. Am. Chem. Soc. 40, 1361-1403 (1918)

34. Freundlich, H.: Over the adsorption in solution. J. Phys. Chem. 57, 385-470 (1906)

35. Li, Y.H., Wang, S., Wei, J., Zhang, X., Xu, C., Luan, Z., Wei, B.: Lead adsorption on carbon nanotubes. Chem. Phys. Lett. 357, 263-266 (2002)

36. Chen, Y., Haddon, R.C., Fang, S., Rao, A.M., Eklund, P.C., Lee, W.H., Smalley, R.E.: Chemical attachment of organic functional 
groups to single-walled carbon nanotube material. J. Mater. Res. 13, 2423-2431 (1998)

37. Imamoglu, M., Tekir, O.: Removal of copper(II) and lead(II) ions from aqueous solutions by adsorption on activated carbon from a new precursor hazelnut husks. Desalination 228, 108-113 (2008)

38. Xu, D., Tan, X., Chen, C., Wang, X.: Removal of Pb(II) from aqueous solution by oxidized multiwalled carbon nanotubes. J. Hazard. Mater. 154, 407-416 (2008)

39. Perez-Aguilar, N., Muñoz-Sandoval, E., Diaz-Flores, P., RangelMendez, J.: Adsorption of cadmium and lead onto oxidized nitrogendoped multiwall carbon nanotubes in aqueous solution: equilibrium and kinetics. J. Nanopart. Res. 12, 467-480 (2010)

40. Jahangiri, M., Kiani, F., Tahermansouri, H., Rajabalinezhad, A.: The removal of lead ions from aqueous solutions by modified multi-walled carbon nanotubes with 1-isatin-3-thiosemicarbazone. J. Mol. Liq. 212, 219-226 (2015)

41. Zhang, C., Sui, J., Li, J., Tang, Y., Cai, W.: Efficient removal of heavy metal ions by thiol functionalized superparamagnetic carbon nanotubes. Chem. Eng. J. 210, 45-52 (2012)

42. Saleh, T.A.: Nanocomposite of carbon nanotubes/silica nanoparticles and their use for adsorption of $\mathrm{Pb}(\mathrm{II})$ : from surface properties to sorption mechanism. Desalin. Water Treat. 57, 10730-10744 (2016)

43. Hu, J., Shao, D., Chen, C., Sheng, G., Li, J., Wang, X., Nagatsu, M.: Plasma-induced grafting of cyclodextrin onto multiwall carbon nanotube/iron oxides for adsorbent application. J. Phys. Chem. B 114, 6779-6785 (2010)

44. Hsieh, S.H., Horng, J.J.: Adsorption behavior of heavy metal ions by carbon nanotubes grown on microsized $\mathrm{Al}_{2} \mathrm{O}_{3}$ particles. J. Univ. Sci. Technol. 14, 77-84 (2007)

45. Yang, S., Hu, J., Chen, C., Shao, D., Wang, X.: Mutual effects of $\mathrm{Pb}$ (II) and humic acid adsorption on multiwalled carbon nanotubes/polyacrylamide composites from aqueous solutions. Environ. Sci. Technol. 45, 3621-3627 (2011)

46. Ouki, S.K., Kavannagh, M.: Performance of natural zeolites for the treatment of mixed metal-contaminated effluents. Waste Manag. Res. 15, 383-394 (1997)

47. Benguell, B., Benaissa, H.: Cadmium removal from aqueous solutions by chitin: kinetic and equilibrium studies. Water Res. 36, 2463-2474 (2002)

48. Gu, H., Lou, H., Tian, J., Liu, S., Tang, Y.: Reproducible magnetic carbon nanocomposites derived from polystyrene with superior tetrabromobisphenol A adsorption performance. J. Mater. Chem. A 4, 10174-10185 (2016)

49. Gu, H., Lou, H., Ling, D., Xiang, B., Guo, Z.: Polystyrene controlled growth of zerovalent nanoiron/magnetite on a sponge-like carbon matrix towards effective $\mathrm{Cr}(\mathrm{VI})$ removal from polluted water. RSC Adv. 6, 110134-110145 (2016) 